\title{
Human amnion mesenchymal stem cells attenuate atherosclerosis by modulating macrophage function to reduce immune response
}

\author{
XIUFANG WEI $^{1}$, GUANG SUN ${ }^{1}$, XIAOXUE ZHAO $^{2}$, QIANQIAN WU ${ }^{1}$, LING CHEN $^{1}$, \\ YICHI XU ${ }^{1}$, XINING PANG $^{3}$ and GUOXIAN QI ${ }^{1}$ \\ ${ }^{1}$ Department of Geriatric Cardiology, The First Affiliated Hospital of China Medical University, Shenyang, Liaoning 110001; \\ ${ }^{2}$ Department of Cardiology, Central Hospital Affiliated to Shenyang Medical College, Shenyang, Liaoning 110024; \\ ${ }^{3}$ Department of Stem Cells and Regenerative Medicine, National Health Commission of China and Key Laboratory of \\ Medical Cell Biology, Ministry of Education of China, China Medical University, Shenyang, Liaoning 110122, P.R. China
}

Received February 20, 2019; Accepted June 28, 2019

DOI: $10.3892 /$ ijmm.2019.4286

\begin{abstract}
Mesenchymal stem cells (MSCs) show immunosuppressive activities and alleviate atherosclerosis (AS) formation in apolipoprotein E-knockout (apoE-KO) mice. Human amnion mesenchymal stem cells (hAMSCs), a particular population of mesenchymal stem cells, have been shown to have immunomodulatory abilities. The present study investigated the effects of hAMSCs treatment on early atherosclerotic plaque formation and the progression of established lesion in apoE-KO mice. In total, 36 mice were fed with a high-fat diet. Mice were subjected to hAMSCs-injection treatment simultaneously with high-fat diet (early treatment) or after 8 weeks of high-fat diet (delayed treatment). In each treatment, mice were divided into three groups: i) hAMSCs group with hAMSCs treatment; ii) PBS group injected with PBS; and iii) control group without injection. Histological results showed that the plaque area in the aortic arch of mice was significantly reduced after hAMSCs treatment in the early and delayed treatment groups. In addition, immunohistochemical analysis suggested that the accumulation of macrophages was significantly decreased after hAMSCs treatment. Similarly, the release of the pro-inflammatory cytokine tumor necrosis factor- $\alpha$ was
\end{abstract}

Correspondence to: Dr Guoxian Qi, Department of Geriatric Cardiology, The First Affiliated Hospital of China Medical University, 155 Nanjing North Street, Shenyang, Liaoning 110001, P.R. China

E-mail: 13604924212@163.com

Dr Xining Pang, Department of Stem Cells and Regenerative Medicine, National Health Commission of China and Key Laboratory of Medical Cell Biology, Ministry of Education of China, China Medical University, 77 Puhe Street, Shenyang, Liaoning 110122, P.R. China

E-mail: pangxining@126.com

Key words: human amnion mesenchymal stem cells, atherosclerosis, macrophages, NF- $\kappa \mathrm{B}$ also decreased, whereas the release of the anti-inflammatory cytokine interleukin-10 was increased. In addition, hAMSCs treatment suppressed the phosphorylation of p65 and inhibitor of $\kappa \mathrm{B}-\alpha$, suggesting that $N F-\kappa \mathrm{B}$ pathway was involved in the hAMSCs-mediated suppression of immune response. In conclusion, hAMSCs treatment was effective in reducing immune response, which is the one of the major causes of AS, eventually leading to a significant reduction in size of atherosclerotic lesions.

\section{Introduction}

Cardiovascular diseases have attracted increasing attention in the research community due to the fact that are the leading causes of mortalities worldwide, presenting the largest morbidity and mortality rates (1). Atherosclerosis (AS) is the main cause of cardiovascular disease $(2,3)$, which is an attractive topic due to its complex pathogenesis and the involvement of multiple cell types (4). Inflammation is an important factor in AS, and it is involved in each stage of the disease (5). Inflammation can oxidize the low-density lipoproteins, inducing the chemotaxis of monocyte, leading to the differentiation of monocytes into macrophage foam cells and the secretion of active molecules, eventually causing the formation of atherosclerotic plaques (3). The modified oxidized low-density lipoproteins can act as antigens, aggravating the inflammatory response in the arterial vessels, ultimately affecting the stability of the AS plaque $(2,6,7)$. Therefore, an increasing number of studies have reported that anti-inflammatory treatments are effective methods to alleviate AS (8-10).

Among all the cells that take part in the AS process, macrophages have an important role, not only in the uptake of cholesterol lipoproteins, becoming foam cells, but in cytokine production in the atherosclerotic area (11). As the largest number of inflammatory cells in the AS lesion, macrophages can produce pro-inflammatory, such as tumor necrosis factor (TNF) $\alpha$, and anti-inflammatory cytokines, such as interleukin (IL)-10. In addition, previous studies have demonstrated that pro-inflammatory cytokines can promote AS development, whereas anti-inflammatory cytokines have an anti-atherosclerotic effect $(12,13)$. 
Currently, drug therapy for atherosclerosis includes, in particular, the use of statins, which were shown to have a significant effect in reducing the risk of cardiovascular disease (14). Statins have anti-inflammatory effects that lower the concentration of lipids, thus benefiting patients with cardiovascular disease (3). However, many patients cannot tolerate statin drugs or cannot follow long-term treatments, and do not show the expected reduction in lipid levels (3). In addition, large clinical trials have shown that the reduction of cardiovascular risk by statins treatment is still unsatisfactory (15-17). Some patients continue to suffer from the expected cardiovascular events under statin treatment (3). Therefore, it is necessary to find new methods for the treatment of atherosclerosis aimed to inhibit the development of atherosclerosis by reducing inflammation or suppressing the formation of foam cells.

An increasing number of studies have shown that stem cells have an important role in tissue repair and anti-inflammation (18). In particular, numerous experimental studies have proven that mesenchymal stem cells (MSCs) have anti-inflammatory and immunological properties (19-24). At present, MSCs are used to control the development of AS $(5,25)$. Previous studies suggested that MSCs can regulate the role of various inflammatory cells such as macrophages and inhibit the formation of plaques by inhibiting inflammatory responses $(5,25)$.

Recently, multiple studies focused on the role of macrophages in atherosclerosis progression (5,25-27). Macrophages can be classified into M1 macrophages and M2 macrophages according their phenotype, M1 macrophages show dynamically shifting in a range spanning from a pro-inflammatory phenotype, and M2 macrophages show a pro-regenerative phenotype (28). The functions of macrophages are mediated primarily by a complex milieu of soluble mediators that influence local cells $(29,30)$. MSCs can induce the polarization to M2 macrophages, which modulate inflammation and immune response by secreting a variety of cytokines that inhibit several aspects involved in AS development (18).

MSCs were first identified in the bone marrow and subsequently in various tissues such as the synovial membrane (31-33). Human amnion MSCs (hAMSCs), which are isolated from amniotic membrane of human placenta, not only have MSCs characteristics and differentiation potential, but also have many advantages such as low risk of tumor formation, low immunogenicity, strong paracrine function and are easily obtained $(34,35)$. These properties make hAMSCs a suitable potential resource for clinical applications (36). The immunomodulatory properties of hAMSCs have been previously identified, including the influence of T-cell proliferation, the inhibition of dendritic cell differentiation and maturation (37), and the inhibition of macrophage-mediated production of inflammatory cytokines $(38,39)$. Therefore, the present study investigated the effect of hAMSCs on the inhibition of the formation and progression of atherosclerotic plaque in apolipoprotein E-knockout (apoE-KO) mice by regulating the function of inflammatory macrophages, suggesting a therapeutic potential of hAMSCs for the treatment of AS.

\section{Materials and methods}

hAMSCs isolation and cell culture. The amnion samples of normal pregnancies were obtained after caesarean section.
The present study was approved by the Ethical Committee for Medical Scientific Research of the First Affiliated Hospital at China Medical University [approval no. (2016)105] and the informed consent was obtained from all patients. In the present study, 32 pregnant women (age range, 25-35 years) were enrolled between July 2016 and December 2016 in the First Affiliated Hospital at China Medical University. The isolation and culture of hAMSCs were performed as previously described (40). Briefly, the amnion samples were treated with collagenase IV (Sigma-Aldrich; Merck KGaA) and DNase I (Takara Bio, Inc.) after manual separation from the chorion. hAMSCs were cultured at $37^{\circ} \mathrm{C}$ in DMEM/F12 (Hyclone; GE Healthcare Life Sciences) containing 10\% FBS (Hyclone; GE Healthcare Life Sciences), 1\% penicillin streptomycin (Gibco; Thermo Fisher Scientific, Inc.) and $10 \mathrm{mmol} / \mathrm{ml}$ fibroblast growth factor-2 (PeproTech, Inc.). hAMSCs were passaged every $72 \mathrm{~h}$ for 3-6 times.

Flow cytometric characterization of hAMSCs. Flow cytometry was used to detect stem cell-related cell surface markers on hAMSCs. hAMSCs were cultured at $37^{\circ} \mathrm{C}$ for $48 \mathrm{~h}$ prior to analysis. Then, cells were harvested, washed, resuspended with $1 \mathrm{X}$ PBS containing $1 \%$ BSA. Cells were counted and diluted to $5 \times 10^{6}$ cells $/ 100 \mathrm{ml}$ and incubated for $1 \mathrm{~h}$ on ice. Subsequently, cells were incubated with monoclonal phycoerythrin-conjugated antibodies for CD44 (cat. no. 338807), CD90 (cat. no. 32810), CD31 (cat. no. 303105), CD45 (cat. no. 368509), stage-specific embryonic antigen 4 (SSEA-4; cat. no. 330405) and major histocompatibility complex, class II, DR (HLA-DR; cat. no. 307605). All of the antibodies were purchased from BioLegend, Inc. Appropriate isotype-matched antibodies were used as negative controls (BD Biosciences). The data from 10,000 viable cells were acquired with a flow cytometer and analyzed using the FACSDiva software (version 6.2; BD Biosciences).

Animals. In total, $36 \mathrm{C} 57 \mathrm{BL} / 6$ apoE-KO male mice (age, 8 weeks; weight, $25 \pm 2 \mathrm{~g}$ ) were obtained from Beijing HFK Bioscience Co. Ltd. (5). All the animals were housed in an environment with a temperature of $22 \pm 1^{\circ} \mathrm{C}$, relative humidity of $50 \pm 1 \%$ and a light/dark cycle of $12 \mathrm{~h}$ and received drinking water ad libitum. In addition, mice were fed with high-fat diet containing $21 \%$ fat and $0.15 \%$ cholesterol from 8 weeks of age. Furthermore, all animal studies, including the mice euthanasia procedure, were done in compliance with the regulations and guidelines of China Medical University institutional animal care and conducted according to AAALAC guideline and IACUC guidelines (approval no. CMU2016028). The experiments performed on human samples and animals were approved by the Ethical Committee for Medical Scientific Research of the First Affiliated Hospital at China Medical University [approval no. (2016)105]. To examine the role of hAMSCs on the prevention and treatment of atherosclerosis, hAMSCs were administered by tail vein injection as previously described (5,27). For the early-hAMSCs treatment study, 18 apoE-KO mice were treated with hAMSCs with high-fat diet for 10 weeks. In the delayed-hAMSCs treatment study, 18 apoE-KO mice were first fed with high-fat diet for 8 weeks, and were then treated with hAMSCs for 10 weeks. In each treatment regimen, mice were randomly divided into three groups 
( $n=6$ in each group): i) hAMSCs group, containing mice treated with hAMSCs $\left(5 \times 10^{5} \mathrm{hAMSCs}\right.$ in $\left.150 \mu \mathrm{l} \mathrm{PBS}\right)$ once every other week; ii) PBS group, containing mice treated with $150 \mu \mathrm{l}$ PBS once every other week; and iii) control group, without treatment. 'Control 1' group was defined as the control group in the early-hAMSCs treatment and 'control 2' group was defined as the control group in the late-hAMSCs treatment.

After the treatment, all mice were anesthetized by intraperitoneal injection of pentobarbital $(50 \mathrm{mg} / \mathrm{kg})$. Lipid analysis was performed on the serum samples obtained from blood collected from the left ventricles of mice at the end of the studies. The serum total cholesterol, triglyceride (TG) and high-density lipoprotein (HDL)-cholesterol were measured by enzymatic methods using a commercially available kit (Sekisui Chemical Co., Ltd.) with a Hitachi Automatic Analyzer 7600 (Hitachi, Ltd.). Low-density lipoprotein (LDL)-cholesterol was calculated using the Friedewald formula: LDL-cholesterol = total cholesterol-HDL-cholesterol-(TG/5) (41). Non-HDL-cholesterol was calculated by subtracting the quantity of HDL-cholesterol from total cholesterol (42).

Histological and immunohistochemical analysis. After left ventricle perfusion, the aorta with the aorta root, the aortic arch and the iliac artery was collected. The aortic root was removed, fixed with $4 \%$ paraformaldehyde at room temperature and embedded in paraffin. In total, five sections (thickness, $5 \mu \mathrm{m}$ ) of each aortic root were stained with hematoxylin and eosin for $5 \mathrm{~min}$ at room temperature. Pathological changes in each group were observed using a light microscope (Olympus Corporation; magnification, x200).

Paraffin-embedded sections were exposed to increasing ethanol concentrations. After incubation with 3\% hydrogen peroxide solution for $15 \mathrm{~min}$ at room temperature to inhibit endogenous peroxidase activity, $0.1 \mathrm{M}$ sodium citrate solution was used for antigen retrieval at $120^{\circ} \mathrm{C}$ for $90 \mathrm{sec}$ and $5 \% \mathrm{BSA}$ was used to block non-specific signal at room temperature for $20 \mathrm{~min}$, sections were incubated with anti-CD68 rabbit polyclonal antibody (1:500; cat. no. GB11067; Wuhan Servicebio Co., Ltd.) overnight at $4^{\circ} \mathrm{C}$. The sections were washed with PBS and incubated with Goat anti-rabbit IgG (horseradish peroxidase-conjugated; 1:1,000, cat. no. ab6721; Abcam) at room temperature for $30 \mathrm{~min}$. The sections were then visualized with 3,3'-diaminobenzidine that was incubated with the samples at room temperature for $1 \mathrm{~min}$. The nuclei were counterstained with hematoxylin at room temperature for $2 \mathrm{~min}$. The macrophage coverage was determined by the percentage of the positive stained area in relation to the total plaque area. Samples were observed using a light microscope (Olympus Corporation; magnification, x200).

Western blotting. Total protein lysates were extracted from the aortic tissue using RIPA lysis buffer (Beyotime Institute of Biotechnology) supplemented with protease inhibitors, according to the manufacturer's instructions. The protein concentration was measured using a bicinchoninic protein assay kit (Beyotime Institute of Biotechnology). The samples with equal amount of total protein $(20 \mu \mathrm{g}$ in each lane) were then heated at $100^{\circ} \mathrm{C}$ for $5 \mathrm{~min}$ in loading buffer, separated by $10 \%$ SDS-PAGE (Beijing Transgen Biotech Co., Ltd.) and transferred to PVDF membranes (EMD Millipore). PVDF membranes were blocked with $5 \%$ skim milk for $1 \mathrm{~h}$ at room temperature and incubated overnight at $4{ }^{\circ} \mathrm{C}$ with the following primary antibodies: TNF $\alpha$ monoclonal antibody $(1: 1,000$; cat. no. 60291-1-lg; ProteinTech Group, Inc.), IL-10 antibody (1:500; cat. no. DF6894; Affinity Biosciences), phosphorylated (p-)NF-кB p65 rabbit mAb (1:500; cat. no. 3033; Cell Signaling Technology, Inc.), p-inhibitor of $\kappa \mathrm{B}-\alpha(\mathrm{I} \kappa \mathrm{B} \alpha)$ rabbit (1:500; cat. no. 2859; Cell Signaling Technology, Inc.), NF-кB p65 rabbit mAb (1:1,000; cat. no. 8242; Cell Signaling Technology, Inc.), I $\kappa \mathrm{B} \alpha$ rabbit $\mathrm{mAb}$ (1:500; cat. no. 4812; Cell Signaling Technology, Inc.) and mouse anti- $\beta$ actin monoclonal antibody (1:500; cat. no. TA-09; OriGene Technologies, Inc.). The membrane was incubated for $1 \mathrm{~h}$ at room temperature with the secondary peroxidase-conjugated antibody goat anti-rabbit IgG (1:1,000; cat. no. zb2301; OriGene Technologies, Inc.) or the peroxidase-conjugated goat anti-mouse $\operatorname{IgG}(1: 1,000$; cat. no. zb2305; OriGene Technologies, Inc.), the membranes were visualized using an ECL kit (Thermo Fisher Scientific, Inc.) and analyzed using ImageJ software (version 1.5.1; National Institutes of Health).

Reverse transcription-quantitative PCR (RT-qPCR). Total RNA was extracted from the aortic tissues using TRIzol reagent (Invitrogen; Thermo Fisher Scientific, Inc.). RNA concentration was detected using the NanoDrop 2000 (Thermo Fisher Scientific, Inc.). RT was performed using the PrimeScript RT Reagent kit (Takara Bio, Inc.). The reaction was performed as follows: $37^{\circ} \mathrm{C}$ for $15 \mathrm{~min}$ followed by $85^{\circ} \mathrm{C}$ for $5 \mathrm{sec}$. qPCR was performed using the SYBR PrimeScript RT-PCR kit (Takara Bio, Inc.) with an ABI 7500 Sequence Detection system (Applied Biosystems; Thermo Fisher Scientific, Inc.). PCR was conducted using the following thermocycling conditions: Initial denaturation at $95^{\circ} \mathrm{C}$ for $30 \mathrm{sec}$, followed by 40 cycles of $95^{\circ} \mathrm{C}$ for $5 \mathrm{sec}$ and $60^{\circ} \mathrm{C}$ for $20 \mathrm{sec}$. All the gene expression results were normalized to the expression of GAPDH. The primer sequences were as follows: TFN $\alpha$ forward, 5'-AGA GTGGTCAGGTTGCCTCTG-3' and reverse, 5-GGCTCT GTGAGGAAGGCTGT-3'; IL-10 forward, 5'-GGCTCTGTG AGGAAGGCTGT-3' and reverse, 5'-TTCCGATAAGGCTTG GCAAC-3'; and GAPDH forward, 5'-GGTTGTCTCCTG CGACTTCA-3' and reverse, 5'-TGGTCCAGGGTTTCTTAC TCC-3'. Normalization and fold changes were calculated using the $2^{-\Delta \Delta \mathrm{Cq}}$ method (43).

Statistical analysis. The results are presented as the mean \pm SD from at least three independent experiments. Statistical analysis was performed using one-way ANOVA followed by least significant difference post hoc test using SPSS 22.0 (IBM Corp.). $\mathrm{P}<0.05$ was considered to indicate a statistically significant difference.

\section{Results}

Characterization of hAMSCs. After purification, hAMSCs were identified to be positive for CD44 and CD90, and negative for CD31 and CD45 (Fig. 1). The present data indicated that hAMSCs had stem cell characteristics, as they expressed SSEA-4 (44), and low immunogenicity, as hAMSCs were negative for HLA-DR (45). 

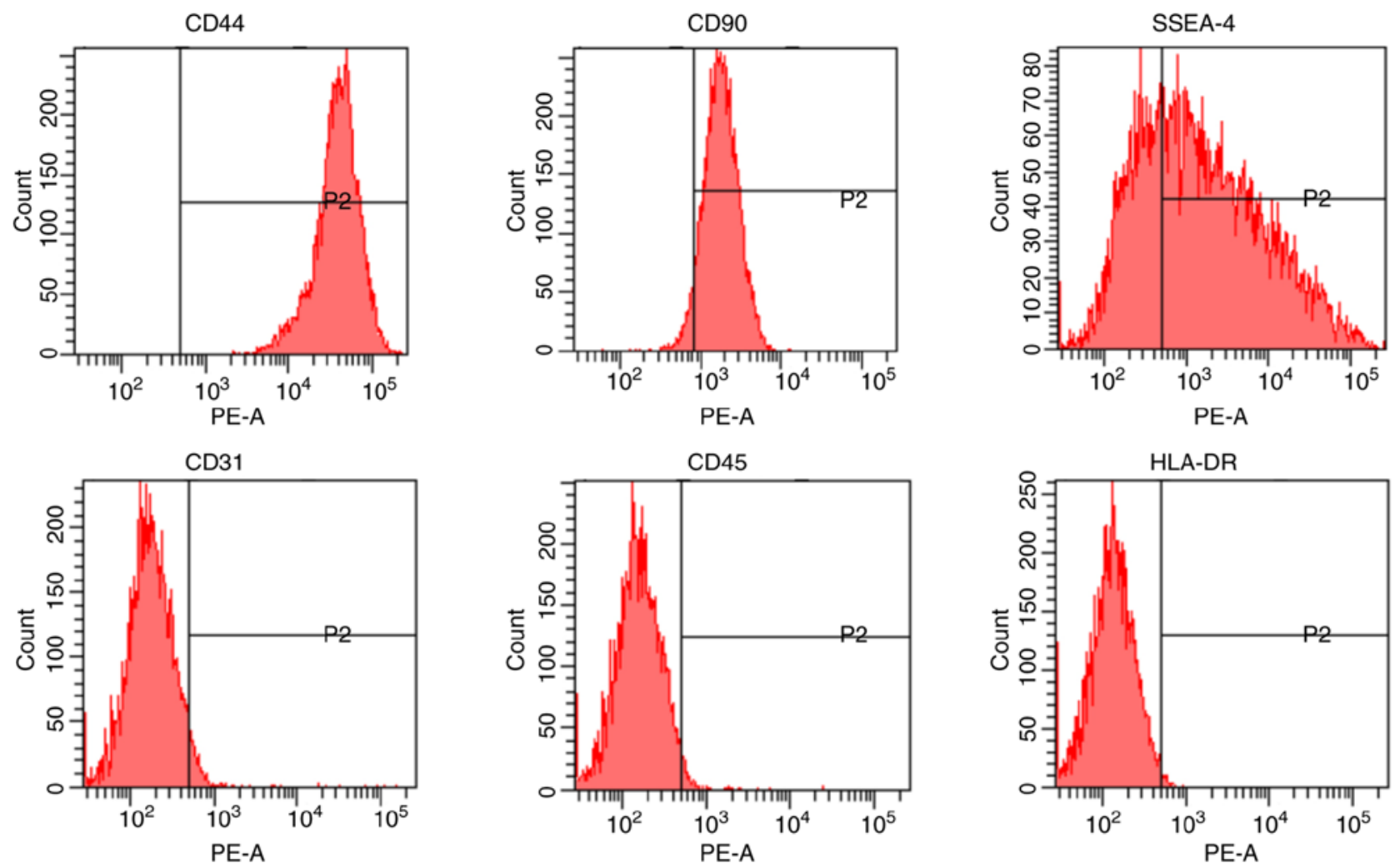

Figure 1. Characterization of hAMSCs. hAMSCs were characterized by analyzing the expression of the cell surface markers CD44, CD90, SSEA-4, CD31, CD45 and HLA-DR using flow cytometry. hAMSCs, human amniotic mesenchymal stem cells; PE, phycoerythrin; HLA-DR, major histocompatibility complex, class II, DR; SSEA-4, stage-specific embryonic antigen 4.

Effects of hAMSCs treatment on weight and plasma lipid levels. The weight of the mice was calculated. No significant difference was observed between the hAMSCs treatment group and the control group either in early hAMSCs treatment study or in late hAMSCs treatment study ( $\mathrm{n}=6$ in each group). In addition, treatment with hAMSCs did not affect the concentration of plasma lipids (Fig. 2).

Effects of hAMSCs treatment on the development of atherosclerotic lesions. After 10 weeks of hAMSCs treatment, histologic analysis of sections taken from the aortic root was performed. A significant decrease was found in plaque size in mice treated with hAMSCs injection compared with control mice in early and late hAMSCs treatment groups, which suggested that hAMSCs treatment inhibited the plaque formation and progression of established lesions. The significant difference between control 1 and control 2 suggested that prolonging the high-fat diet worsened the atherosclerotic lesions. Moreover, no significant difference was observed in lesion size between late hAMSCs treatment group and early control group, which presented initial signs of atherosclerotic lesions, indicating that treatment with hAMSCs did not regress the established lesions (Fig. 3).

Effects of hAMSCs treatment on macrophage accumulation in atherosclerotic plaque. To detect the effect of hAMSCs treatment on the accumulation of macrophages, immunohistochemical analysis was performed on the aortic root. The present results showed that hAMSCs treatment suppressed the accumulation of macrophages in both early and late
hAMSCs treatment groups; the number of macrophages in atherosclerotic plaque was significantly decreased in mice treated with hAMSCs compared with the PBS group control mice. However, the accumulation of macrophage may not be associated with a prolonged high-fat diet, as no significant difference between control 1 and control 2 was identified (Fig. 4).

hAMSCs modulates cytokine expression in a mouse model of $A S$. Macrophages are the most important source of cytokine production (46). To assess the inhibitory effect of hAMSCs on cytokine secretion, the expression of the pro-inflammatory cytokine TNF $\alpha$ and the anti-inflammatory cytokine IL-10 was determined from atherosclerotic arteries by western blotting and RT-qPCR analysis. In contrast with the control group, TNF $\alpha$ expression was significantly decreased, whereas IL-10 expression was increased in the hAMSCs treatment group in both early hAMSCs treatment group and late hAMSCs treatment group (Fig. 5).

hAMSCs suppresses the phosphorylation of $p 65$ and $I \kappa B \alpha$ in a mouse model of $A S$. To determine whether $\mathrm{NF}-\kappa \mathrm{B}$ signaling pathway was involved in the regulatory effect of hAMSCs on atherosclerotic plaque in a mouse model of AS, the phosphorylation level of two NF- $\mathrm{BB}$ signaling molecules, p65 and IкB $\alpha$, were investigated. Notably, the phosphorylation level of p65 and $\mathrm{I} \kappa \mathrm{B} \alpha$ are associated with the activation of the NF- $\kappa \mathrm{B}$ pathway (47). The results of western blot analysis showed that the levels of p-p65 and I $\mathrm{B} \alpha$ were downregulated in mice treated with hAMSCs injection compared with the 


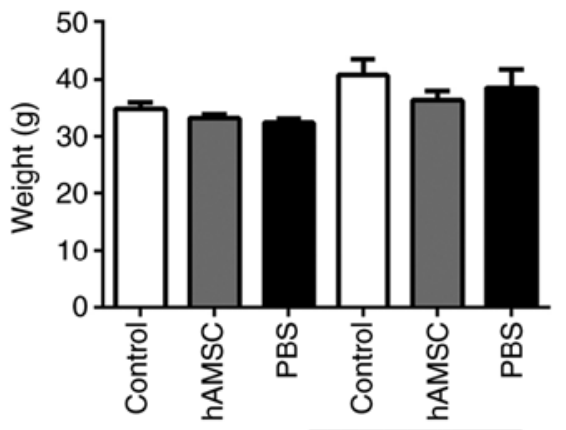

Fed with high-fat diet for 8 weeks

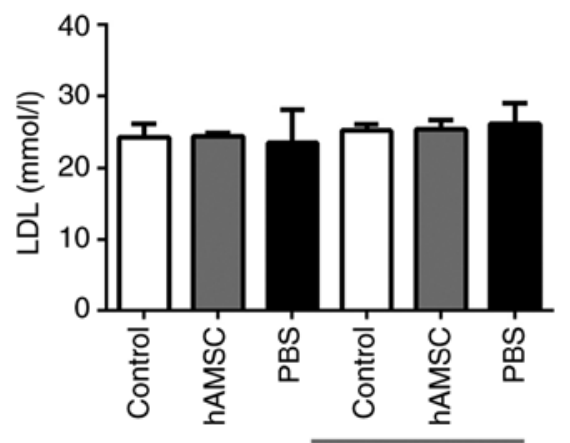

Fed with high-fat diet for 8 weeks

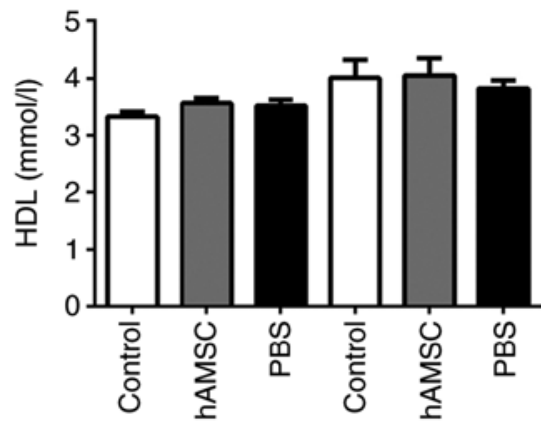

Fed with high-fat diet for 8 weeks

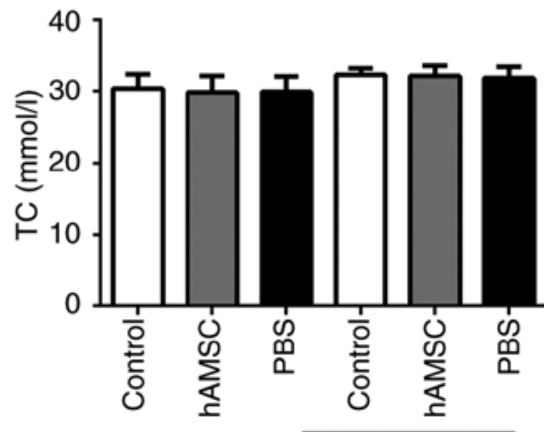

Fed with high-fat diet for 8 weeks
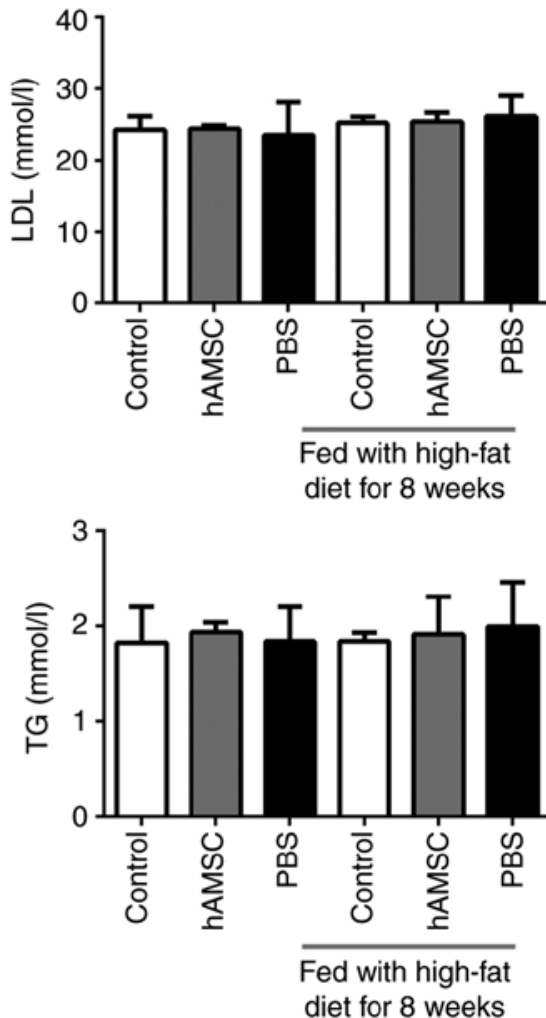

Figure 2. Effects of early and late hAMSCs treatment on weight and lipid levels in apolipoprotein E-knockout mice. Mice were treated with hAMSCs or PBS concomitantly with or after 8 weeks of high-fat diet. Control mice were not treated. There were no significant differences in weight or lipid index in mice treated with hAMSCs compared with control mice in both treatment regimens. TC, total cholesterol; TG, triglyceride; LDL, low density lipoprotein; HDL, high density lipoprotein; hAMSCs, human amniotic mesenchymal stem cells.

control mice in both early hAMSCs treatment group and in late hAMSCs treatment group (Fig. 6).

\section{Discussion}

In the present study, hAMSCs injection was identified to reduce AS development through the decrease of macrophage accumulation and the inhibition of inflammatory response of aortic arteries. The present results suggested that the levels of secreted cytokines, including TNF $\alpha$ and IL-10, was modulated by hAMSCs through the NF- $\mathrm{B}$ pathway.

AS is a disease in which atherosclerotic plaques develop inside the arteries (48). Macrophages are the most abundant immune cell type in atherosclerotic lesions and have an essential role during all stages of the disease, from lesion initiation to plaque rupture (49). Atherosclerotic plaques and their macrophage content can regress, as previously shown in particular murine models of hypercholesterolemia reversal $(48,50,51)$. Decrease of macrophage accumulation and functional regulation in atherosclerotic lesions could represent a potential target in the treatment of AS. The present study suggested that systemic administration of hAMSCs decreased AS development and progression when simultaneously applied with high-fat diet. hAMSCs inhibited AS progression after 8 weeks when combined with high-fat diet in apoE-KO mice. In addition, the therapeutic benefit of hAMSCs could be explained by the modulation of the inflammatory response, as after hAMSCs treatment the accumulation of macrophages in the plaque of aortic root was decreased. Importantly, the function of macrophage in the plaque was not investigated, and further studies are required to examine this phenomenon. In addition, the expression of the pro-inflammatory cytokine $\mathrm{TNF} \alpha$ was significantly downregulated, whereas the anti-inflammatory cytokine IL-10 was upregulated in aortic arches. However, the present study did not identify direct and molecular evidence associating hAMSCs and macrophages recruitment and function in the plaque region, and further studies are required to examine this process.

Numerous previous studies have shown that MSCs can reduce AS development by inhibiting the inflammatory response $(5,25,27,52)$. MSCs might be directly involved in AS plaque formation, as Li et al (5) observed that MSCs are capable of migrating to AS plaque and selectively locating near macrophages, and Fang et al (52) observed 5-bromo-2-deoxyuridine-positive MSCs in AS plaque. Nevertheless, Frodermann et al (25) observed that MSCs primarily accumulate in the lungs after intravenous injection, and only a few MSCs could migrate to the lymph nodes of the heart and the aorta. These previous results suggests that MSCs do not necessarily have an anti-atherosclerotic role due to long-term engraftment, but may act via the paracrine signaling pathway, since MSCs have a significant paracrine function (53). Our previous study suggested that hAMSCs have a strong paracrine function, which could significantly promote the proliferation and tube formation of endothelial cells (40). Similar experiments on the therapeutic improvement of MSCs without significant engraftment have been reported in various animal models $(39,54)$. Due to the limited time and research 

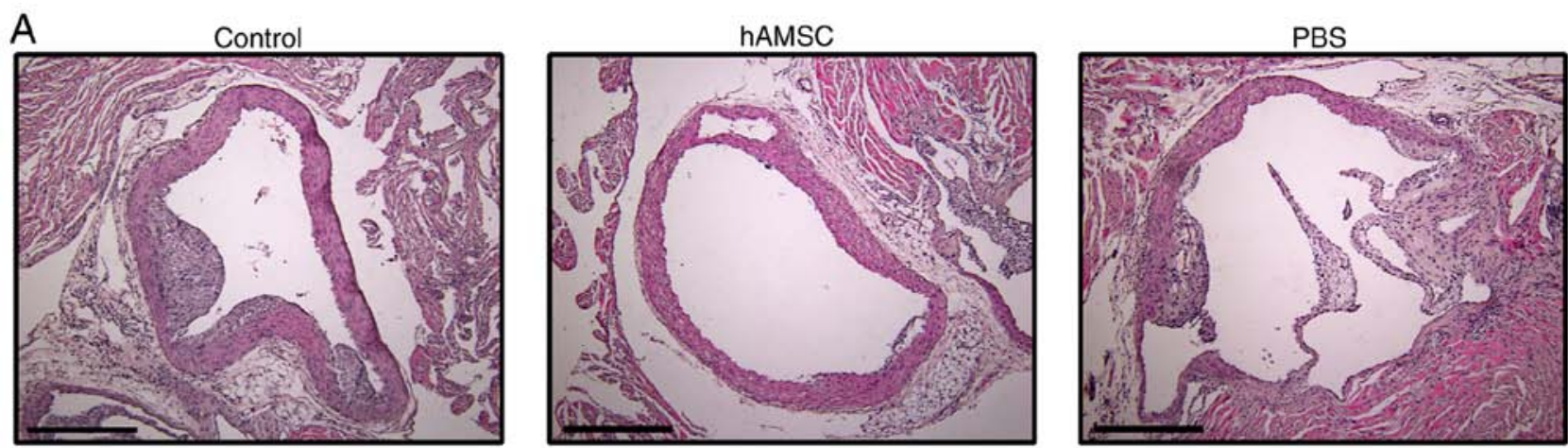

B

Fed with high-fat diet for 8 weeks
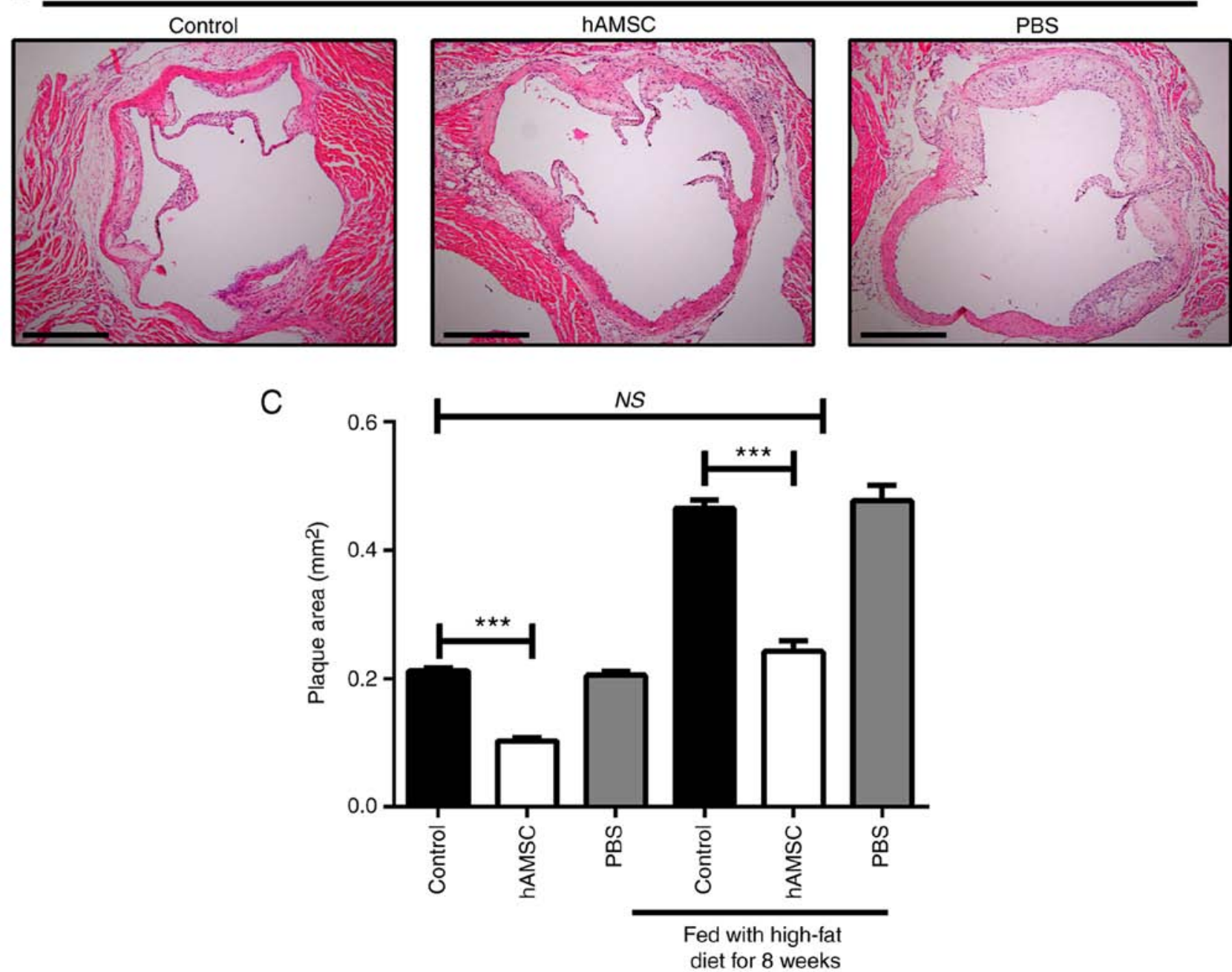

Figure 3. Effects of early and late hAMSCs treatment on progression of atherosclerotic lesions in the aortic root of apolipoprotein E-knockout mice. (A) Representative photomicrographs of atherosclerotic lesions in untreated mice, or mice treated with hAMSCs or PBS concomitantly with high-fat diet. (B) Representative photomicrographs of atherosclerotic lesions in untreated mice, or mice treated with hAMSCs or PBS after 8 weeks of high-fat diet. (C) Quantification. Plaque area was significantly decreased in mice treated with hAMSCs $\left(0.11 \pm 0.01 \mathrm{~mm}^{2}\right) \mathrm{compared}$ with control mice $\left(0.21 \pm 0.01 \mathrm{~mm}^{2}\right)$ in the early treatment group. Plaque area was also significantly decreased in mice treated with hAMSCs $\left(0.24 \pm 0.04 \mathrm{~mm}^{2}\right)$ compared with control mice $\left(0.47 \pm 0.03 \mathrm{~mm}^{2}\right)$ in the late treatment group. There were no significant differences in plaque area between late hAMSCs treatment group and early control group, suggesting that hAMSCs treatment did not induce a regression of the established atherosclerotic lesion. $\mathrm{n}=6$ in each group. Scale bar, $500 \mu \mathrm{m}$. ${ }^{* * * *} \mathrm{P}<0.001$. NS, not significant; hAMSCs, human amniotic mesenchymal stem cells.

funds, the present study did not investigate the fate of the injected hAMSCs, which requires to be addressed by further studies in the future.

The development of atherosclerotic plaque is a multistep inflammatory process. Macrophages have an important role in all stages of AS and they serve as effectors in the process of
AS (55). The important pathological changes in AS include the accumulation of macrophages in endothelial lesions (56). These macrophages can become foam cells after uptake of modified lipoproteins, which trigger the release of cytokines in macrophages via the activation of a heterodimer formed by Toll-like receptors 4 and 6, aggravating the inflammatory reaction (57). 
A

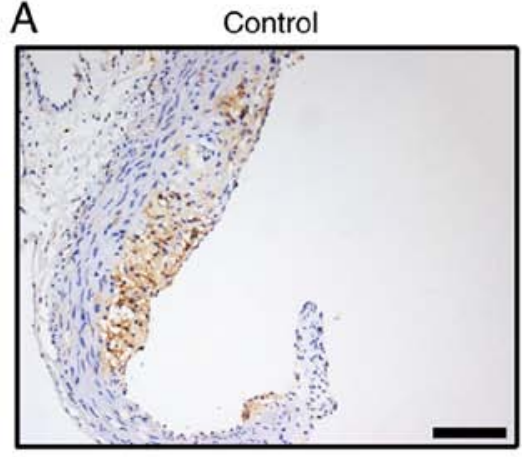

B

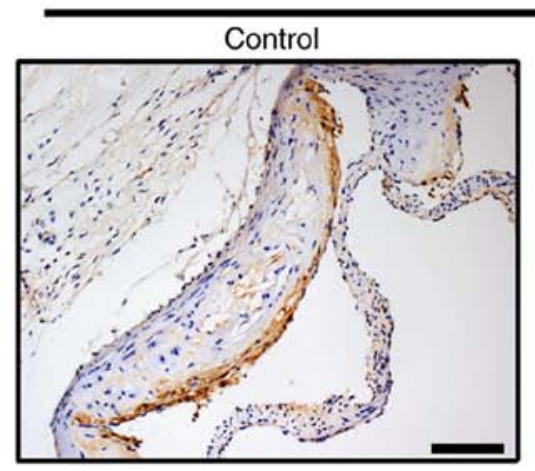

C

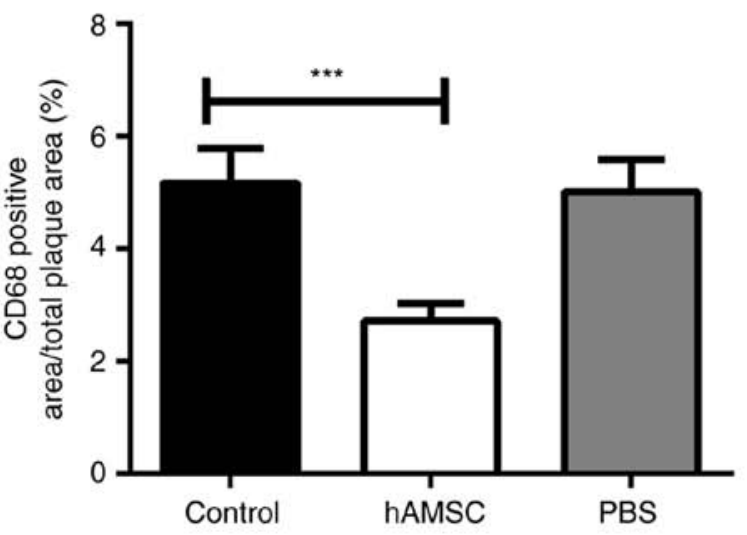

hAMSC

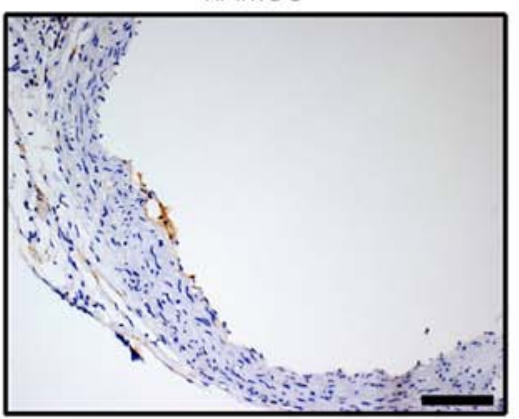

Fed with high-fat diet for 8 weeks
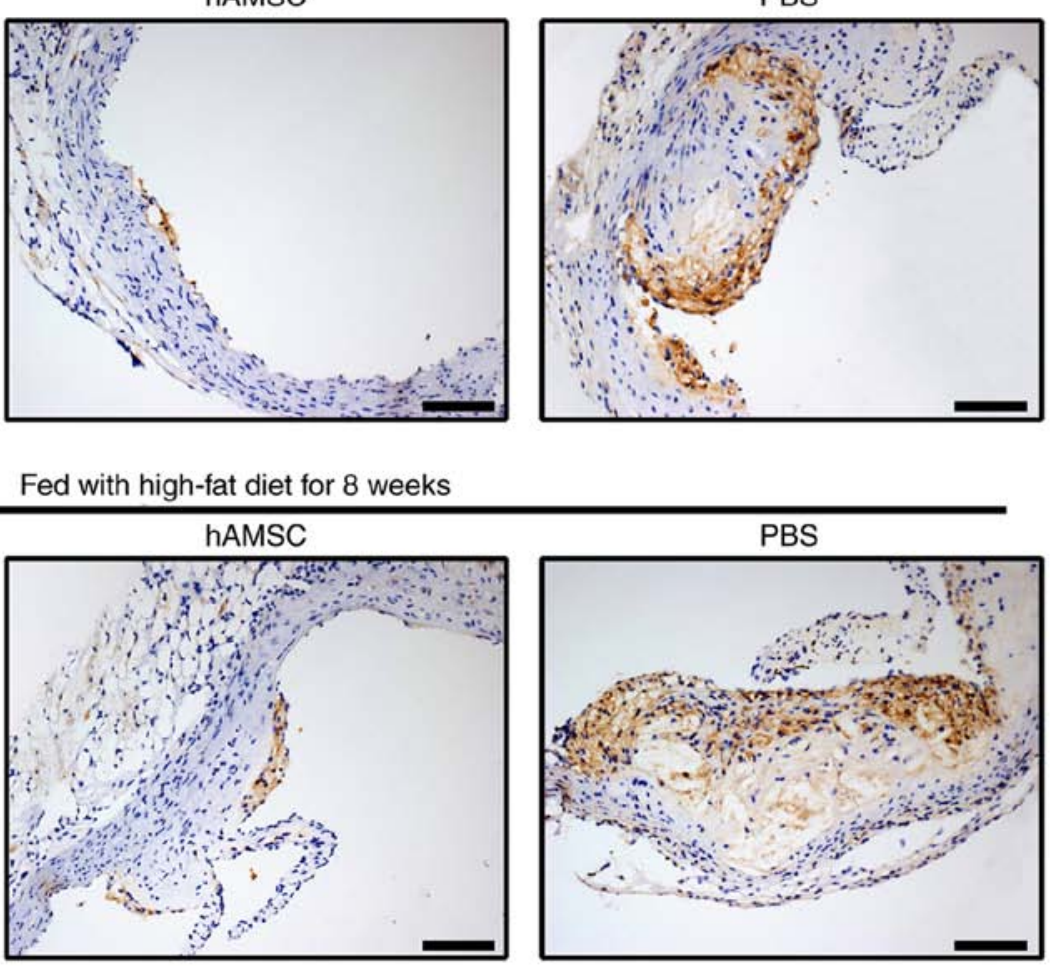

PBS

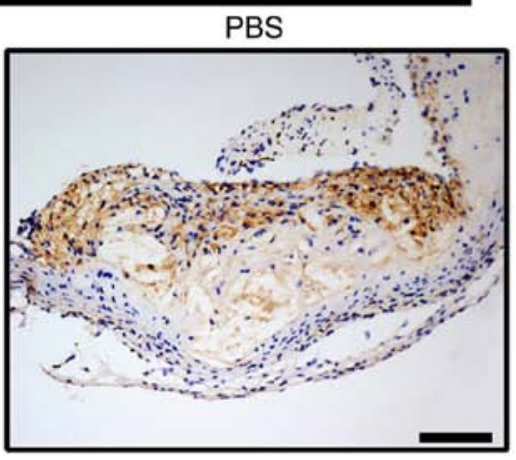

D

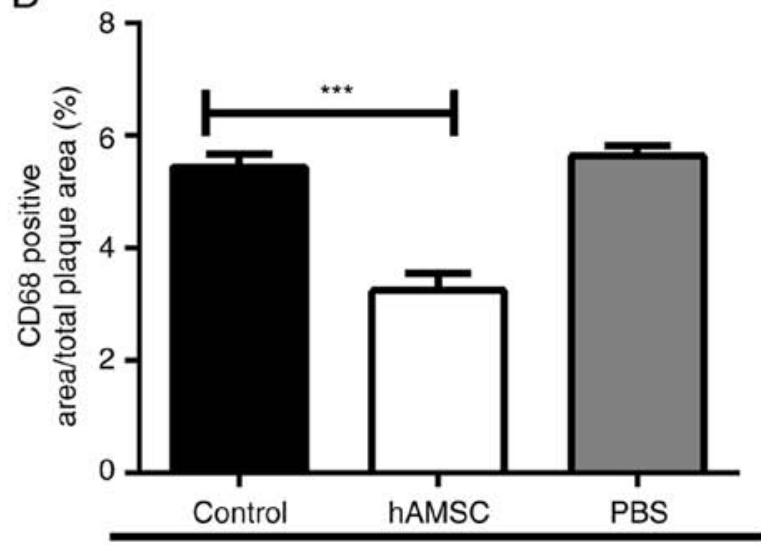

Fed with high-fat diet for 8 weeks

Figure 4. Effects of early and late hAMSCs treatment on macrophage accumulation in the plaque of aortic root of apolipoprotein E-knockout mice. (A) Representative photomicrographs of macrophages in untreated mice, or mice treated with hAMSCs or PBS concomitantly with high-fat diet. (B) Representative photomicrographs of macrophages in untreated mice, or mice treated with hAMSCs or PBS after 8 weeks of high-fat diet. Accumulation of macrophages in the plaques was significantly decreased in mice treated with hAMSCs compared with control mice in the early $(2.72 \pm 0.98$ and $5.17 \pm 1.93 \%$, respectively) and late treatment groups (3.23 \pm 0.97 and $5.44 \pm 0.71 \%$, respectively). Brown staining indicates macrophages. Quantification for the (C) early and (D) late treatments. $\mathrm{n}=6$ in each group. Scale bar, $100 \mu \mathrm{m} .{ }^{* * *} \mathrm{P}<0.001$. hAMSCs, human amniotic mesenchymal stem cells. hAMSCs, human amniotic mesenchymal stem cells.

Therefore, reducing the aggregation of macrophages and the formation of foam cells in atherosclerotic plaque is essential to control the inflammatory response during AS. According to previous studies, MSCs could reduce the aggregation of macrophages in the arterial intima (39), inhibit the formation of macrophage-foam cells (27), decrease the expression of inflammatory factor $\mathrm{TNF} \alpha$ and increase the expression of anti-inflammatory factors such as IL-10 (5). In the present study, hAMSCs treatment was found to decrease the accumulation of macrophages in atherosclerotic plaque. Notably, the present results may be caused by the systemic influence of the immune response in response to the injection of exogenous cells into the bloodstream. In addition, hAMSCs treatment may influence local tissue micro-environment, inducing the polarization to M2 macrophages and influencing the function of macrophages (58). However, the molecule mechanism underlying the association between hAMSCs treatment and macrophage recruitment and function require further investigation. A previous study observed that following co-culture with hAMSCs, the levels of TNF $\alpha$ and IL-1 $\beta$ in lipopolysaccharide-stimulated macrophages is significantly reduced, which may be caused by inhibition of the NF- $\mathrm{B}$ pathway (38). 
A
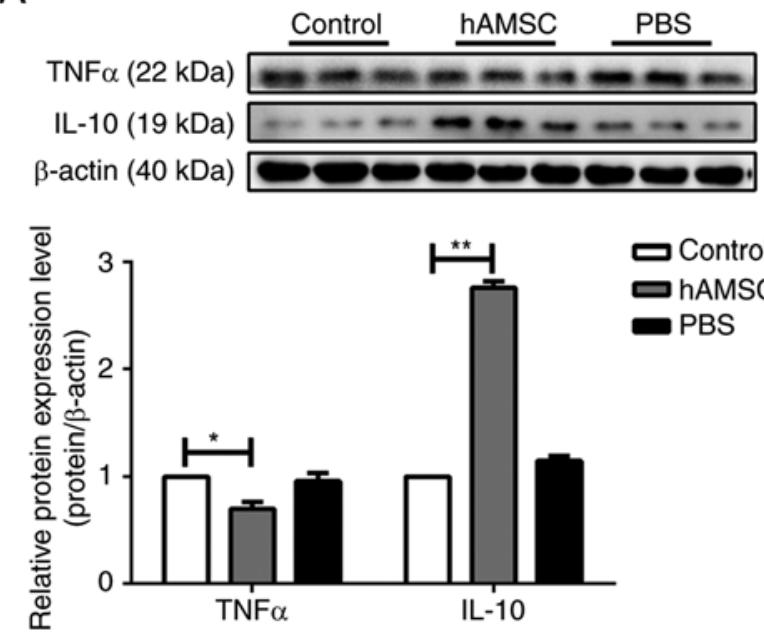

B

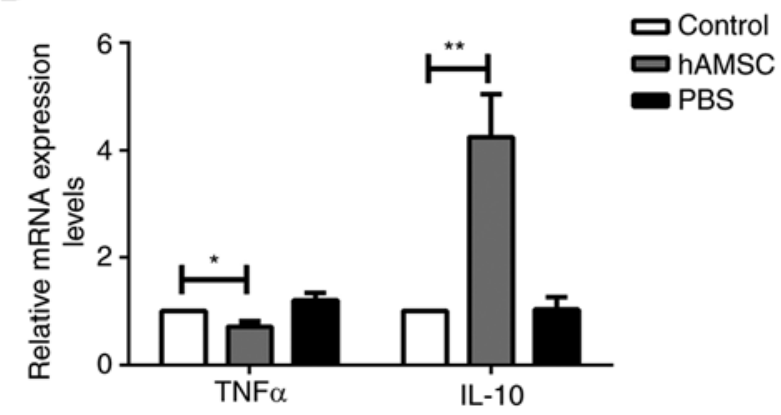

Fed with high-fat diet for 8 weeks
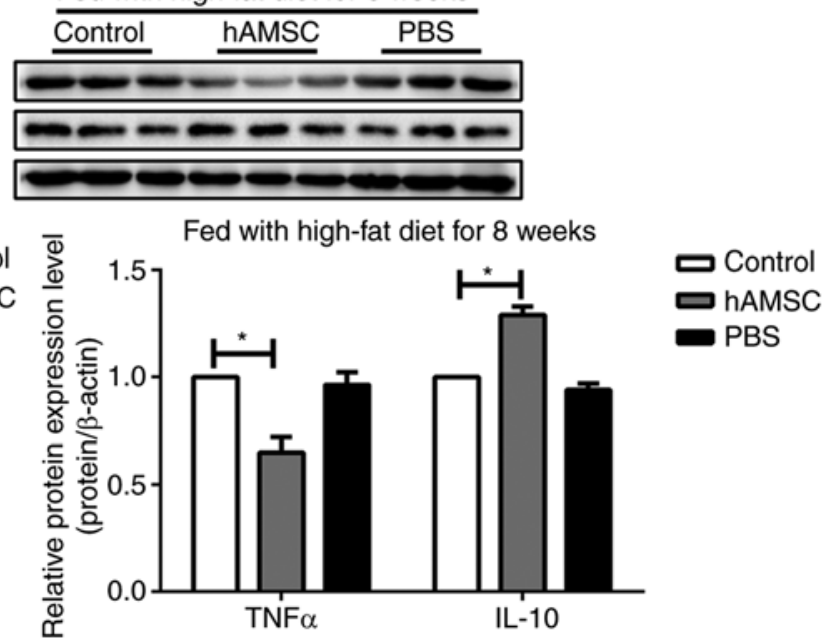

Fed with high-fat diet for 8 weeks

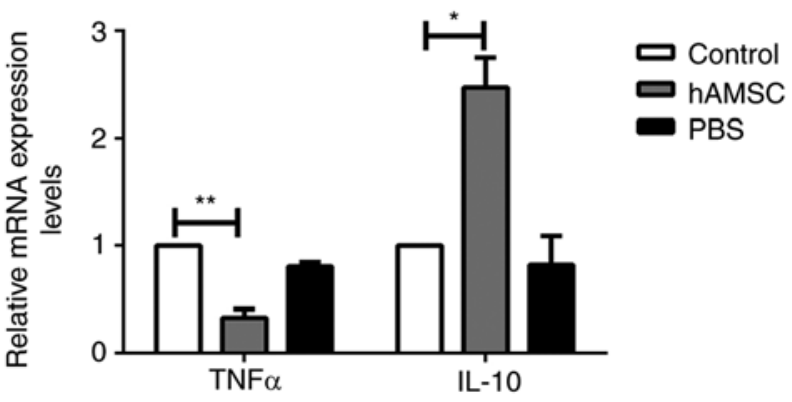

Figure 5. Effects of early and late hAMSCs treatment on cytokine release in the artery of apolipoprotein E-knockout mice. Mice were treated with hAMSCs or PBS concomitantly with or after 8 weeks of high-fat diet. Control mice were not treated. The expression of the pro-inflammatory cytokine TNF $\alpha$ was significantly downregulated, whereas the expression of the anti-inflammatory cytokine IL-10 was significantly upregulated in mice treated with hAMSCs compared with control mice in early and late treatment groups, as determined by (A) western blotting and (B) reverse transcription-quantitative PCR. ${ }^{\mathrm{P}}<0.05$, ${ }^{* *} \mathrm{P}<0.01$. hAMSCs, human amniotic mesenchymal stem cells; TNF, tumor necrosis factor; IL, interleukin.

NF- $\kappa B$ pathway is an important transcription factor that regulates both innate and adaptive immune responses and is essential for the expression of a number of genes involved in the inflammatory response, such as TNF $\alpha$ and IL-6 (38). These genes can directly activate the NF- $\mathrm{KB}$ pathway, promoting the inflammatory response, which involves the phosphorylation of p65 and IкB $\alpha(47,59)$. Since MSCs have an anti-inflammatory role in an NF- $\kappa \mathrm{B}$-dependent manner (5), hAMSCs may promote the downregulation of TNF $\alpha$ and upregulation of IL-10 via the NF- $\mathrm{kB}$ pathway. In the present study, following hAMSCs treatment, the phosphorylation levels of p65 and I $\mathrm{B} \alpha$ were downregulated, suggesting an inhibition of the NF- $\kappa B$ pathway. Therefore, the anti-inflammatory function of hAMSCs may be mediated by the inhibition of the NF- $\mathrm{KB}$ pathway.

Previous studies reported that the anti-inflammatory role of MSCs caused not only the decrease in TNF $\alpha$ level, but also the increase in IL-10 levels $(60,61)$. Notably, IL-10 was observed to decrease the synthesis of TNF $\alpha$ (60). Nemeth et al (62) reported the macrophages isolated from MSCs-treated septic mice produce significantly higher levels of IL-10 than those isolated from non-treated mice, suggesting a temporary reprogramming of monocytes and macrophages. IL-10 was observed to promote atherosclerotic lesion stability (13), and the present results suggested that MSCs can increase the levels of IL-10 in addition to reducing AS development by modulating the levels of anti-inflammatory molecules. However, further studies are required to investigate whether the blockage of IL-10 could reduce the effects of hAMSCs treatment. In the present study, an increase in IL-10 in the aortic vasculature was observed after hAMSCs treatment; therefore, the effect of hAMSCs on AS stabilization should be further investigated.

In the present study, no significant effects of hAMSCs on mice blood lipid levels were observed. To the best of our knowledge, the report by Frodermann et al (25) is the only study that reported a decrease in blood lipid levels following MSC treatment. Notably, in this previous study, MSCs were isolated from the bone marrow and not from the amniotic fluid, and these previous results may be associated with the different source of MSCs. Additionally, in the study by Frodermann et al (25), the decrease in blood lipid levels in mice was identified 4-5 weeks after MSCs treatment, suggesting that MSCs may indirectly regulate the level of blood lipids by regulating other cellular functions. Previous studies observed that hAMSCs have paracrine function and can secret various types of cytokines, chemokines and growth factors, which are important for intercellular interactions $(40,53)$. Therefore, further studies are necessary to examine the role of these cytokines in AS progression and development.

In summary, the present study examined the effect of hAMSCs on AS. In addition, hAMSCs treatment was found 

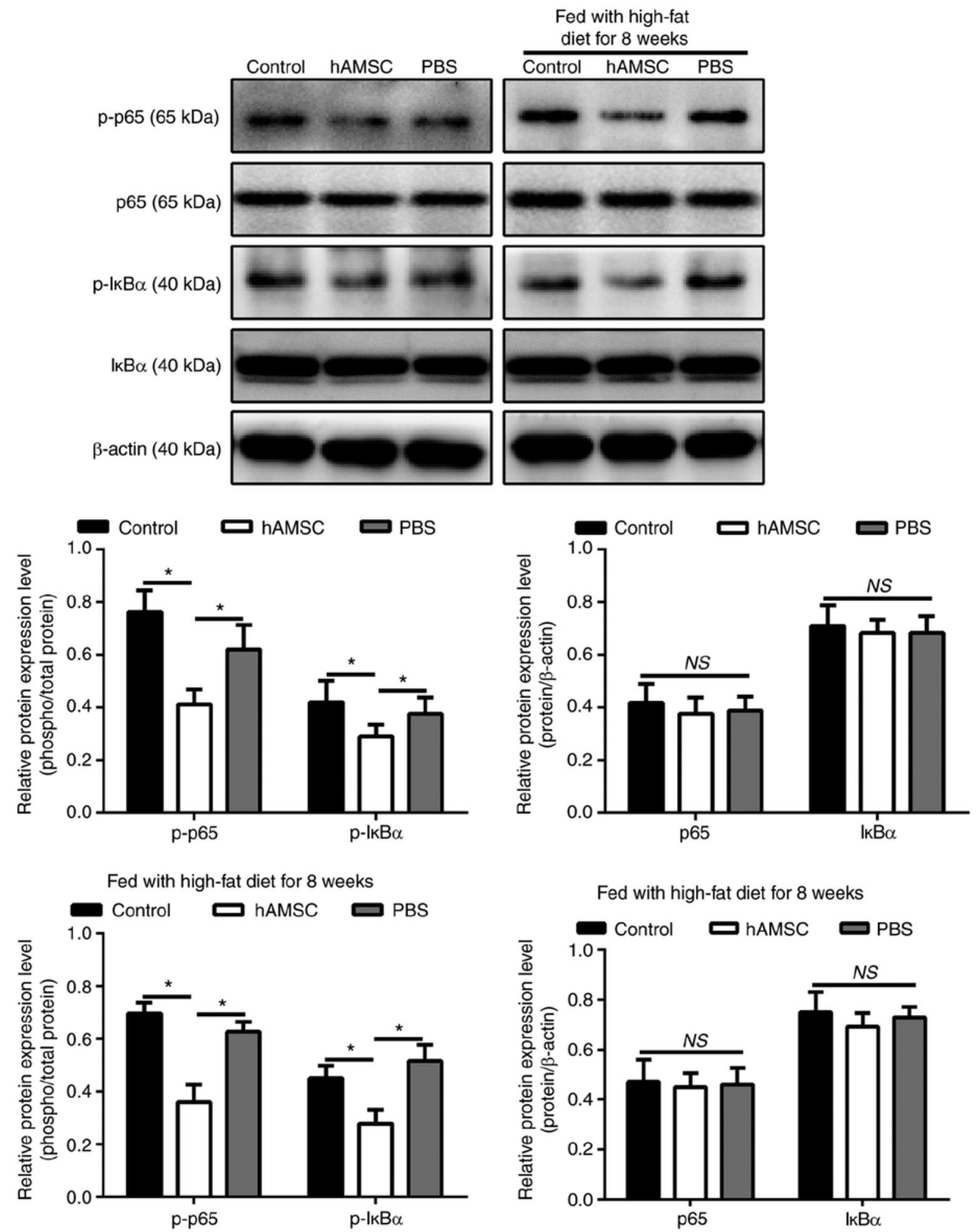

Figure 6. Effects of early and late hAMSCs treatment on the inhibition of the NF- $\mathrm{B}$ pathway in apolipoprotein E-knockout mice. Mice were treated with hAMSCs or PBS concomitantly with or after 8 weeks of high-fat diet. Control mice were not treated. Phosphorylation levels of p65 and IкB $\alpha$, indicating activation of the NF- $\mathrm{NB}$ pathway, were downregulated in mice treated with hAMSCs compared with control mice in early and late treatment groups as determined by western blot analysis. $\beta$-actin was used as an internal control. hAMSCs, human amniotic mesenchymal stem cells; I $\mathrm{B} \alpha$, inhibitor of $\kappa \mathrm{B} \alpha$; $\mathrm{p}-$, phosphorylated; ${ }^{*} \mathrm{P}<0.05$, NS, not significant.

to be effective in reducing the immune response, one of the major pathways involved in AS, leading to a significant reduction in the size of atherosclerotic lesions. Cytotherapy has attracted increasing interest, and finding the most effective methodology to employ stem cells is an important aspect for identifying the optimal treatment methods. The present study suggested that hAMSCs may represent a promising cell source for clinical applications.

\section{Acknowledgements}

Not applicable. 


\section{Funding}

This study was supported by the National Basic Research Program of China (grant no. 2012CB518103), the National Natural Science Foundation of China (grant no. 81450017), the Science and Technology Planning Project of Liaoning Province (grant no. 2014305012), the Science and Technology Planning Project of Shenyang (grant no. F14-201-4-00), the Shenyang Key Laboratory Project (grant no. F15-157-1-00), and the National Natural Science Foundation of China (grant no. 81300038).

\section{Availability of data and materials}

The datasets used and/or analyzed during the current study are available from the corresponding author on reasonable request.

\section{Authors' contributions}

XW and GQ conceived and designed the study and drafted the manuscript. GS, XZ and QW performed experiments and interpreted the results. LC, YX and XP analyzed the data. GQ contributed to the acquisition of funding. All authors read and approved the final manuscript.

\section{Ethics approval and consent to participate}

Approval to conduct the study was obtained from Ethics Committee for Medical Scientific Research in the First Affiliated Hospital of China Medical University [approval no. (2016)105]. All animal studies, including the mice euthanasia procedure, were performed in compliance with the regulations and guidelines of China Medical University institutional animal care and conducted according to AAALAC guideline and IACUC guidelines (63) and were approved by the Ethics Committee (approval no. CMU2016028).

\section{Patient consent for publication}

Not applicable.

\section{Competing interests}

The authors declare that they have no competing interests.

\section{References}

1. Mozaffarian D, Benjamin EJ, Go AS, Arnett DK, Blaha MJ, Cushman M, de Ferranti S, Després JP, Fullerton HJ, Howard VJ, et al: Heart disease and stroke statistics-2015 update: A report from the american heart association. Circulation 131: e29-e322, 2015.

2. Frostegård J: Immunity, atherosclerosis and cardiovascular disease. BMC Med 11: 117, 2013.

3. Zhang X, Huang F, Chen Y, Qian X and Zheng SG: Progress and prospect of mesenchymal stem cell-based therapy in atherosclerosis. Am J Transl Res 8: 4017-4024, 2016.

4. Wu DJ, Xu JZ, Wu YJ, Jean-Charles L, Xiao B, Gao PJ and Zhu DL: Effects of fasudil on early atherosclerotic plaque formation and established lesion progression in apolipoprotein E-knockout mice. Atherosclerosis 207: 68-73, 2009.

5. Li Q, Sun W, Wang X, Zhang K, Xi W and Gao P: Skin-derived mesenchymal stem cells alleviate atherosclerosis via modulating macrophage function. Stem Cells Transl Med 4: 1294-1301, 2015.
6. De Jager SC and Pasterkamp G: Crosstalk of lipids and inflammation in atherosclerosis: The PRO of PGRN? Cardiovase Res 100: 4-6, 2013.

7. Johansson ME, Zhang XY, Edfeldt K, Lundberg AM, Levin MC, Borén J, Li W, Yua XM, Folkersen L, Eriksson P, et al: Innate immune receptor NOD2 promotes vascular inflammation and formation of lipid-rich necrotic cores in hypercholesterolemic mice. Eur J Immunol 44: 3081-3092, 2014.

8. Khan R, Spagnoli V, Tardif JC and L'Allier PL: Novel anti-inflammatory therapies for the treatment of atherosclerosis. Atherosclerosis 240: 497-509, 2015.

9. Mendel I, Yacov N, Harats D and Breitbart E: Therapies targeting innate immunity for fighting inflammation in atherosclerosis. Curr Pharm Des 21: 1185-1195, 2015.

10. Asciutto G, Dias NV, Edsfeldt A, Alm R, Fredrikson GN, Gonçalves I and Nilsson J: Low levels of IgG autoantibodies against the apolipoprotein $\mathrm{B}$ antigen p210 increases the risk of cardiovascular death after carotid endarterectomy. Atherosclerosis 239: 289-294, 2015.

11. Tedgui A and Mallat Z: Cytokines in atherosclerosis: Pathogenic and regulatory pathways. Physiol Rev 86: 515-581, 2006.

12. Little PJ, Chait A and Bobik A: Cellular and cytokine-based inflammatory processes as novel therapeutic targets for the prevention and treatment of atherosclerosis. Pharmacol Ther 131: 255-268, 2011.

13. Han $\mathrm{X}$ and Boisvert WA: Interleukin-10 protects against atherosclerosis by modulating multiple atherogenic macrophage function. Thromb Haemost 113: 505-512, 2015.

14. Shapiro MD and Fazio S: From lipids to inflammation: New approaches to reducing atherosclerotic risk. Circ Res 118: 732-749, 2016.

15. Hague W, Forder P, Simes J, Hunt D, Tonkin A and Investigators L: Effect of pravastatin on cardiovascular events and mortality in 1516 women with coronary heart disease: Results from the long-term intervention with pravastatin in ischemic disease (LIPID) study. Am Heart J 145: 643-651, 2003.

16. Libby P: The forgotten majority: Unfinished business in cardiovascular risk reduction. J Am Coll Cardiol 46: 1225-1228, 2005.

17. Serban MC, Banach M and Mikhailidis DP: Clinical implications of the IMPROVE-IT trial in the light of current and future lipid-lowering treatment options. Expert Opin Pharmacother 17: 369-380, 2016.

18. Zhang QZ, Su WR, Shi SH, Wilder-Smith P, Xiang AP, Wong A Nguyen AL, Kwon CW and Le AD: Human gingiva-derived mesenchymal stem cells elicit polarization of $\mathrm{m} 2$ macrophages and enhance cutaneous wound healing. Stem Cells 28: 1856-1868, 2010.

19. Chai NL, Zhang XB, Chen SW, Fan KX and Linghu EQ: Umbilical cord-derived mesenchymal stem cells alleviate liver fibrosis in rats. World J Gastroenterol 22: 6036-6048, 2016.

20. Tan L, Dai T, Liu D, Chen Z, Wu L, Gao L, Wang Y and Shi C: Contribution of dermal-derived mesenchymal cells during liver repair in two different experimental models. Sci Rep 6: 25314, 2016.

21. Xie Z, Hao H, Tong C, Cheng Y, Liu J, Pang Y, Si Y, Guo Y, Zang L, Mu Y and Han W: Human umbilical cord-derived mesenchymal stem cells elicit macrophages into an anti-inflammatory phenotype to alleviate insulin resistance in type 2 diabetic rats. Stem Cells 34: 627-639, 2016.

22. Seebach E, Freischmidt H, Holschbach J, Fellenberg J and Richter W: Mesenchymal stroma cells trigger early attraction of M1 macrophages and endothelial cells into fibrin hydrogels, stimulating long bone healing without long-term engraftment. Acta Biomater 10: 4730-4741, 2014.

23. Braza F, Dirou S, Forest V, Sauzeau V, Hassoun D, Chesné J, Cheminant-Muller MA, Sagan C, Magnan A and Lemarchand P: Mesenchymal stem cells induce suppressive macrophagesthrough phagocytosis in a mouse model of asthma. Stem Cells 34: 1836-1845, 2016.

24. Maria ATJ, Toupet K, Maumus M, Fonteneau G, Le Quellec A, Jorgensen C, Guilpain P and Noël D: Human adipose mesenchymal stem cells as potent anti-fibrosis therapy for systemic sclerosis. J Autoimmun 70: 31-39, 2016.

25. Frodermann V, van Duijn J, van Pel M, van Santbrink PJ, Bot I, Kuiper J and de Jager SC: Mesenchymal stem cells reduce murine atherosclerosis development. Sci Rep 5: 15559, 2015.

26. Bobryshev YV, Ivanova EA, Chistiakov DA, Nikiforov NG and Orekhov AN: Macrophages and their role in atherosclerosis: Pathophysiology and transcriptome analysis. Biomed Res Int 2016: 9582430, 2016. 
27. Wang ZX, Wang CQ, Li XY, Feng GK, Zhu HL, Ding Y and Jiang XJ: Mesenchymal stem cells alleviate atherosclerosis by elevating number and function of CD4(+)CD25 (+)FOXP3 $(+)$ regulatory T-cells and inhibiting macrophage foam cell formation. Mol Cell Biochem 400: 163-172, 2015.

28. Murray PJ, Allen JE, Biswas SK, Fisher EA, Gilroy DW, Goerdt S, Gordon S, Hamilton JA, Ivashkiv LB, Lawrence T, et al: Macrophage activation and polarization: Nomenclature and experimental guidelines. Immunity 41: 14-20, 2014

29. Michaeli S, Dakwar V, Weidenfeld K, Granski O, Gilon O, Schif-Zuck S, Mamchur A, Shams I and Barkan D: Soluble mediators produced by pro-resolving macrophages inhibit angiogenesis. Front Immunol 9: 768, 2018.

30. Triantafyllou E, Woollard KJ, McPhail MJW, Antoniades CG and Possamai LA: The role of monocytes and macrophages in acute and acute-on-chronic liver failure. Front Immunol 9: 2948, 2018.

31. Hu Y, Liao L, Wang Q, Ma L, Ma G, Jiang X and Zhao RC: Isolation and identification of mesenchymal stem cells from human fetal pancreas. J Lab Clin Med 141: 342-349, 2003.

32. Tsai MS, Lee JL, Chang YJ and Hwang SM: Isolation of human multipotent mesenchymal stem cells from second-trimester amniotic fluid using a novel two-stage culture protocol. Hum Reprod 19: 1450-1456, 2004

33. Lee OK, Kuo TK, Chen WM, Lee KD, Hsieh SL and Chen TH: Isolation of multipotent mesenchymal stem cells from umbilical cord blood. Blood 103: 1669-1675, 2004.

34. Kmiecik G, Niklinska W, Kuc P, Pancewicz-Wojtkiewicz J, Fil D, Karwowska A, Karczewski J and Mackiewicz Z: Fetal membranes as a source of stem cells. Adv Med Sci 58: 185-195, 2013.

35. Kim EY, Lee KB and Kim MK: The potential of mesenchymal stem cells derived from amniotic membrane and amniotic fluid for neuronal regenerative therapy. BMB Rep 47: 135-140, 2014

36. Xiao J: Human amniotic stem cells: Ideal seed cells source for regenerative medicine. J Zunyi Med Univ 38: 439-449, 2015.

37. Kronsteiner B, Peterbauer-Scherb A, Grillari-Voglauer R Redl H, Gabriel C, van Griensven M and Wolbank S: Human mesenchymal stem cells and renal tubular epithelial cells differentially influence monocyte-derived dendritic cell differentiation and maturation. Cell Immunol 267: 30-38, 2011.

38. Shu J, He X, Zhang L, Li H, Wang P and Huang X: Human amnion mesenchymal cells inhibit lipopolysaccharide-induced TNF- $\alpha$ and IL-1 $\beta$ production in THP-1 cells. Biol Res 48: 69, 2015.

39. Shoji M, Oskowitz A, Malone CD, Prockop DJ and Pochampally R Human mesenchymal stromal cells (MSCs) reduce neointimal hyperplasia in a mouse model of flow-restriction by transient suppression of anti-inflammatory cytokines. J Atheroscler Thromb 18: 464-474, 2011

40. Wu Q, Fang T, Lang H, Chen M, Shi P, Pang X and Qi G: Comparison of the proliferation, migration and angiogenic properties of human amniotic epithelial and mesenchymal stem cells and their effects on endothelial cells. Int J Mol Med 39: 918-926, 2017.

41. Friedewald WT, Levy RI and Fredrickson DS: Estimation of the concentration of low-density lipoprotein cholesterol in plasma, without use of the preparative ultracentrifuge. Clin Chem 18 499-502, 1972

42. Frost PH and Havel RJ: Rationale for use of non-high-density lipoprotein cholesterol rather than low-density lipoprotein cholesterol as a tool for lipoprotein cholesterol screening and assessment of risk and therapy. Am J Cardiol 81: 26B-31B, 1998

43. Livak KJ and Schmittgen TD: Analysis of relative gene expression data using real-time quantitative PCR and the 2(-Delta Delta C(T)) method. Methods 25: 402-408, 2001.

44. Trusler O, Huang Z, Goodwin J and Laslett AL: Cell surface markers for the identification and study of human naive pluripotent stem cells. Stem Cell Res 26: 36-43, 2018.

45. Fernandez Vallone VB, Romaniuk MA, Choi H, Labovsky V, Otaegui $\mathrm{J}$ and Chasseing NA: Mesenchymal stem cells and their use in therapy: What has been achieved? Differentiation $85: 1-10$, 2013.

46. Murray RZ and Stow JL: Cytokine secretion in macrophages: SNAREs, Rabs, and membrane trafficking. Front Immunol 5: $538,2014$.
47. Liu Z, Han Y, Li L, Lu H, Meng G, Li X, Shirhan M, Peh MT, Xie L, Zhou S, et al: The hydrogen sulfide donor, GYY4137, exhibits anti-atherosclerotic activity in high fat fed apolipoprotein E(-/-) mice. Br J Pharmacol 169: 1795-1809, 2013.

48. Fisher EA: Regression of atherosclerosis: The journey from the liver to the plaque and back. Arterioscler Thromb Vasc Biol 36: 226-235, 2016.

49. Lu X: Impact of macrophages in atherosclerosis. Curr Med Chem 23: 1926-1937, 2016.

50. Feig JE, Parathath S, Rong JX, Mick SL, Vengrenyuk Y, Grauer L, Young SG and Fisher EA: Reversal of hyperlipidemia with a genetic switch favorably affects the content and inflammatory state of macrophages in atherosclerotic plaques. Circulation 123: 989-998, 2011.

51. Potteaux S, Gautier EL, Hutchison SB, van Rooijen N, Rader DJ, Thomas MJ, Sorci-Thomas MG and Randolph GJ: Suppressed monocyte recruitment drives macrophage removal from atherosclerotic plaques of Apoe ${ }^{-/-}$mice during disease regression. J Clin Invest 121: 2025-2036, 2011.

52. Fang SM, Du DY, Li YT, van Rooijen N, Rader DJ, Thomas MJ, Sorci-Thomas MG and Randolph GJ: Allogeneic bone marrow mesenchymal stem cells transplantation for stabilizing and repairing of atherosclerotic ruptured plaque. Thromb Res 131: e253-e257, 2013

53. Yao Y, Huang J, Geng Y, Qian H, Wang F, Liu X, Shang M, Nie S, Liu N, Du X, et al: Paracrine action of mesenchymal stem cells revealed by single cell gene profiling in infarcted murine hearts. PLoS One 10: e0129164, 2015.

54. Togel F, Weiss K, Yang Y, Hu Z, Zhang P and Westenfelder C: Vasculotropic, paracrine actions of infused mesenchymal stem cells are important to the recovery from acute kidney injury. Am J Physiol Renal Physiol 292: F1626-F1635, 2007.

55. Perek B, Kowalska K, Kempisty B, Nowicki A, Jankowski M, Nawrocki MJ and Malińska A: Role of macrophages in the pathogenesis of atherosclerosis and aortocoronary graft disease. J Biol Regul Homeost Agents 32: 1055-1059, 2018.

56. Ding Y, Huang L, Xian X, Yuhanna IS, Wasser CR, Frotscher M, Mineo C, Shaul PW and Herz J: Loss of Reelin protects against atherosclerosis by reducing leukocyte-endothelial cell adhesion and lesion macrophage accumulation. Sci Signal 9: ra29, 2016.

57. Stewart CR, Stuart LM, Wilkinson K, van Gils JM, Deng J, Halle A, Rayner KJ, Boyer L, Zhong R, Frazier WA, et al: CD36 ligands promote sterile inflammation through assembly of a toll-like receptor 4 and 6 heterodimer. Nat Immunol 11: 155-161, 2010.

58. Okabe Y and Medzhitov R: Tissue-specific signals control reversible program of localization and functional polarization of macrophages. Cell 157: 832-844, 2014.

59. Yamamoto $Y$ and Gaynor RB: IkappaB kinases: Key regulators of the NF-kappaB pathway. Trends Biochem Sci 29: 72-79, 2004

60. Putra A, Ridwan FB, Putridewi AI, Kustiyah AR, Wirastuti K, Sadyah NAC, Rosdiana I and Munir D: The role of TNF- $\alpha$ induced MSCs on suppressive inflammation by increasing TGF- $\beta$ and IL-10. Open Access Maced J Med Sci 6: 1779-1783, 2018.

61. Maiti P, Peruzzaro S, Kolli N, Andrews M, Al-Gharaibeh A, Rossignol J and Dunbar GL: Transplantation of mesenchymal stem cells overexpressing interleukin-10 induces autophagy response and promotes neuroprotection in a rat model of TBI. J Cell Mol Med: Jun 4, 2019 (Epub ahead of print). doi: org/10.1111/jcmm.14396.

62. Nemeth K, Leelahavanichkul A, Yuen PS, Mayer B, Parmelee A, Doi K, Robey PG, Leelahavanichkul K, Koller BH, Brown JM, et al: Bone marrow stromal cells attenuate sepsis via prostaglandin $\mathrm{E}(2)$-dependent reprogramming of host macrophages to increase their interleukin-10 production. Nat Med 15: 42-49, 2009

63. Anderson LC: Institutional and IACUC responsibilities for animal care and use education and training programs. ILAR J 48: 90-95, 2007.

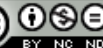

This work is licensed under a Creative Commons Attribution-NonCommercial-NoDerivatives 4.0 International (CC BY-NC-ND 4.0) License. 